\title{
BeeSmart: A Videogame for Supporting Children with Down Syndrome in Eye-hand Coordination and Literacy Skills
}

\author{
Ivan Alejandro Encinas Monroy* \\ ITSON \\ ivanencinasm@gmail.com \\ Edgar Armando Ahumada \\ Solorza \\ ITSON \\ eahumadasolorza4@gmail.com
}

\author{
Oscar Ivan Islas Cruz \\ ITSON \\ oislas03@gmail.com \\ Luis A. Castro \\ ITSON \\ luis.castro@acm.org
}

\author{
Veronica Lizeth Amado Sanchez \\ ITSON \\ veronicaamado4@gmail.com \\ Karina Caro \\ Drexel University \\ karinacaro@drexel.edu
}

\begin{abstract}
Children with Down Syndrome (DS) have deficits in eyehand coordination skills. Deficits in eye-hand coordination could negatively impact the acquisition of literacy skills. In this paper, we present BeeSmart, a gesture-based videogame for supporting eye-hand coordination and literacy skills. BeeSmart is based on the Troncoso's method for literacy, and it uses a gesture tracking sensor. The interaction model of BeeSmart is through air gestures: children use the forefinger to play with the videogame. We describe the four playing levels of BeeSmart and how each one is aimed at supporting specific aspects of the literacy skills using eye-hand coordination.
\end{abstract}

\section{CCS CONCEPTS}

-Social and professional topics $\rightarrow$ People with disabilities;

\section{KEYWORDS}

Eye-hand coordination, literacy, Down Syndrome, videogame.

*Sonora Institute of Technology (ITSON)

\section{INTRODUCTION}

Down Syndrome (DS) is a genetic disorder caused by an extra chromosome, and it occurs in 1 about 700 births. Children with DS can have impairments in cognitive ability and physical growth, mild to moderate developmental disabilities, and a higher risk of some health problems (e.g., Alzheimer disease and epilepsy). Additionally, children with DS might experience deficits in eye-hand coordination [2]. That is, the ability to integrate both visual and motor abilities to accomplish a goal (e.g., reaching a ball). It involves using hands/fingers to reach a visual target. Deficits in eye-hand coordination could impact negatively on the acquisition of literacy skills (i.e., the ability to read and write [1] $]^{1}$ ), as it is one of the main components that contribute to the quality of handwriting [5]. The Troncoso's method is an approach designed to teach children with DS read and write [4] and it is designed to recognize words as a whole, instead of breaking words into letters. The philosophy of the Troncoso's method is to recognize the meaning of written symbols (i.e., words) by association. Children recognize words making relationships between the written word and its associated pictogram.

Gesture-based videogames, digital games that are controlled using gestures without wearing additional aides (e.g., body markers) might have the potential to support eye-hand coordination of children with DS, as they can track hand movements to execute some actions on the screen, and due to its interactivity and engaging and immersive activities [3]. Also, gesture-based videogames can be a promising tool to support the literacy process, combined literacy methods for children with DS such as Troncoso [4], and gamification techniques, such as rewards. In this demo, we present BeeSmart, a gesture-based videogame for supporting eyehand coordination and literacy skills of children with DS, based on the Troncoso's method for literacy.

\footnotetext{
${ }^{1}$ Literacy is an activity based on written and spelling systems.
} 


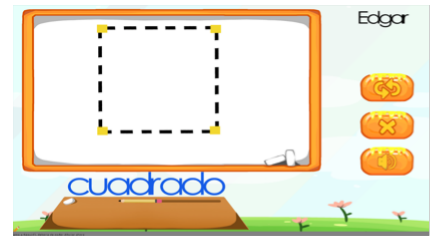

(a)

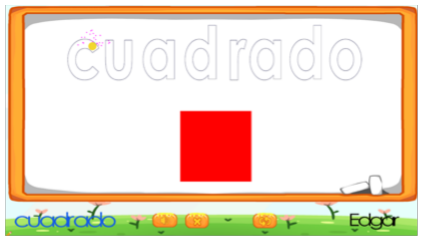

(b)

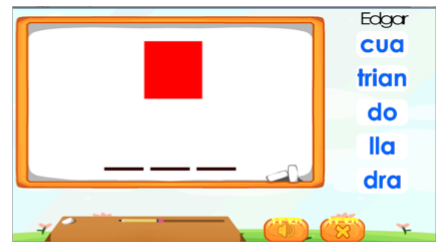

(c)

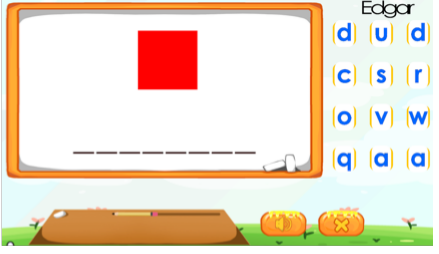

(d)

Figure 1: BeeSmart levels. (a) Level 1; (b) Level 2; (c) Level 3; (d) Level 4.

\section{SYSTEM DESCRIPTION}

BeeSmart has four levels to be played by children with DS and a therapist module, where therapists can review details of the children's game sessions.

\section{BeeSmart Levels}

In each level, children use their forefinger to play the game, using air gestures. That is, children do not need to use any additional device to play the game. At the beginning, the therapist selects the topic (e.g., shapes, colors) and the word (e.g., triangle, yellow) that s/he wants to work with children.

Level 1: Drawing the pictogram. Children use their forefinger to draw pictograms (e.g., a square), following a dottedpath (Figure 1a). The written word associated with the pictogram is also shown on the screen and the pronunciation of the word is played at the beginning of the level. A button to replay the pronunciation of the word is available on the screen. In this level, children follow the dotted-paths, but at the same time, they are seeing the written word on the screen and listening to its pronunciation. The pronunciation feature is available in all levels as well as the pictogram and the written word are always shown on the screen to promote visual association of words and pictograms.

Level 2: Drawing the word.. Children use their forefinger to write a word following a dotted-path (each dot appears once the child joins the previous one) associated with the corresponding pictogram on the screen (Figure 1b).

Level 3: Ordering syllables. Children use their forefinger to move syllables to complete the word associated with the pictogram on the screen (Figure 1c) .

Level 4: Ordering letters. Children use their forefingers to move letters available on the screen to complete the word associated with the pictogram on the screen (Figure 1d).

\section{Therapist Module}

Although each BeeSmart's level requires a cognitive effort that is higher in the last levels and as each child with DS has a different cognitive and motor functioning level, it is the therapist who decides when the child should go on to the next level. To facilitate that, BeeSmart's therapist module enables therapists to review each game session played by children. For each game session, the therapist module shows the child's name, the level played, the duration of the game session (total and by trials), the successful and unsuccessful trials, as well as child's performance (displayed as a percentage of successful trials divided by the total trials).

\section{Implementation Details}

Gestures are tracked using the Intel®RealSense ${ }^{\mathrm{TM}}$ SR300 Sensor. The tracking is activated once the therapist starts a level. Intel ${ }^{\circledR}$ RealSense ${ }^{\mathrm{TM}}$ Sensor tracks children' forefinger, and it enables children to play all levels either with the right or the left hand. BeeSmart is implemented using C\# language and Unity game engine development platform ${ }^{2}$. All data is stored on the local system (i.e., using a PC with an Intel Core i5 5th generation processor and 8 GB RAM).

An introductory video have been recorded available at YouTube at https://goo.gl/zJEM6j

\section{REFERENCES}

[1] V Badillo. 2014. Using picture communication symbols (PCS) for teaching to read and write children with DownâÁŹs syndrome. Int. $\mathcal{F}$ Educ. Sci. Res 4 (2014), 1-8.

[2] Maria Spanò, Eugenio Mercuri, Teresa Randò, Tiziana Pantò, Antonella Gagliano, Sheila Henderson, and Franco Guzetta. 1999. Motor and perceptual-motor competence in children with Down syndrome: variation in performance with age. European fournal of Paediatric Neurology 3, 1 (1999), 7-14.

[3] Debbe Thompson, Tom Baranowski, Richard Buday, Janice Baranowski, Victoria Thompson, Russell Jago, and Melissa Juliano Griffith. 2010. Serious video games for health: How behavioral science guided the development of a serious video game. Simulation \& gaming 41, 4 (2010), 587-606.

[4] María Victoria Troncoso and María Mercedes Del Cerro. 1999. Síndrome de Down: lectura y escritura. Masson Barcelona, Spain.

[5] Cristiana Varuzza, Paola De Rose, Stefano Vicari, and Deny Menghini. 2015. Writing abilities in intellectual disabilities: A comparison between Down and Williams syndrome. Research in developmental disabilities 37 (2015), 135-142.

\footnotetext{
${ }^{2}$ http://unity3d.com
} 